\title{
An Overview of Mental Health During the COVID-19 Pandemic
}

\author{
Patrick J. Chen $^{1 *}$, Yanna Pusica ${ }^{*}$, Dorsa Sohaei ${ }^{2}$, Ioannis Prassas ${ }^{3,5}$, Eleftherios P. \\ Diamandis $^{1-5}$
}

${ }^{1}$ Department of Clinical Biochemistry, University Health Network, Toronto, Canada.

${ }^{2}$ Department of Laboratory Medicine and Pathobiology, University of Toronto, Toronto, Canada.

${ }^{3}$ Department of Pathology and Laboratory Medicine, Mount Sinai Hospital, Toronto, Canada.

${ }^{4}$ Lunenfeld-Tanenbaum Research Institute, Mount Sinai Hospital, Toronto, Canada.

${ }^{5}$ Co-Corresponding authors

*These authors contributed equally to this work

Words 3,415

Abstract words: 193

Figures: 3

Tables: 0

Supplement: 0

To whom correspondence should be addressed:

I. Prassas, Ph.D.

Mount Sinai Hospital, Joseph \& Wolf Lebovic Ctr., 60 Murray St [Box 32]; Flr 6 - Rm L6-201 Toronto, ON, M5T 3L9, Canada

Tel: 416-586-8443; Fax: 416-619-5521;

E-mail: yprassas@gmail.com

and

E.P. Diamandis, Ph.D., M.D.

Mount Sinai Hospital, Joseph \& Wolf Lebovic Ctr., 60 Murray St [Box 32]; Flr 6 - Rm L6-201

Toronto, ON, M5T 3L9, Canada

Tel: 416-586-8443; Fax: 416-619-5521

E-mail: Eleftherios.Diamandis@sinaihealth.ca 


\begin{abstract}
Since its initial outbreak in late 2019, the COVID-19 pandemic has profoundly affected the global community. In addition to the negative health consequences of contracting COVID-19, the implementation of strict quarantine and lockdown measures has also disrupted social networks and devastated the global economy. As a result, there is rising concern that the pandemic has taken a toll on the mental health of the general population. To better understand its impact, an increasing number of studies examined the effects of the pandemic on mental health and psychosocial implications of enforced quarantine and lockdown.

In this article, we aim to review and summarize the findings from a variety of studies that have explored the psychosociological effects of the pandemic and its impact on the mental well-being of the general population. We will also examine how various demographic groups, such as the elderly and youth, can be more susceptible or resilient to the pandemic's mental health effects. We hope to provide a broader understanding of the underlying causes of mental health issues triggered by the pandemic and provide recommendations that may be employed to address mental health issues in the population over the long-term.
\end{abstract}

Keywords: COVID-19, pandemic, mental health, psychological health, anxiety, suicide 


\section{Introduction}

Following its initial outbreak, the Coronavirus Disease 2019 (COVID-19) spread rapidly across the global community, prompting the World Health Organization(WHO) to declare COVID-19 a global pandemic in March 2020 (1). Several countries quickly implemented strict containment measures such as social distancing, school and commercial closures, and home quarantine to reduce the transmission rates within their communities. While these health measures have effectively combated the spread of COVID-19 $(2,3)$, there is concern of the magnification and incoming amplification of mental health issues.

The pandemic has had a profound effect on the mental health of the population due to the disruptions in the social (4), economic (5), and mental fabric of the global community (6-8). There has been an increased prevalence of depression and anxiety disorders, suicide risk, post-traumatic stress symptoms (PTSS), and insomnia among the population. While this is driven, in part, by the fear of contracting or spreading the illness to loved ones $(9,10)$, the psychological effects of quarantine have also contributed to increases in feelings of depression, anxiety, insomnia, and feelings of social disconnect (11-14). Meanwhile, public and commercial closures have significantly disrupted the education and career plans of the young generation (15-17), and growing levels of unemployment and financial debt have also contributed to increased anxiety and depression (18).

The detrimental effects on mental health resulting from the prolonged exposure to the stress imposed by the pandemic are not equally shared among the population (19). Among the vulnerable groups are the elderly (20), particularly those in institutionalized care, the recently unemployed (21), young children and adolescents (22). Essential workers and health care providers may be particularly vulnerable to mental health difficulties due to a greater risk of disease exposure to 
themselves and family members, work intensification and shortages of personal protective equipment $(23,24)$. Moreover, survivors of COVID-19 are susceptible to developing mental health issues due to the discrimination and stigma associated with infection (25). Groups that are more vulnerable to the social, economic and physical impacts of COVID-19 such as racialized individuals, immigrants and refugees, indigenous communities, and low-wage workers are likely, in turn, more vulnerable to mental health effects as well (26-29).

As the COVID-19 pandemic and lockdowns continue, there has been an increase of interest in the long-term mental health consequences. This article aims to summarize the current literature for factors that contribute to mental distress in isolation, anxiety and depression, suicide risk, PTSS, and sleeping disorders. To provide a broader understanding of the current landscape of the population's mental well-being during the COVID-19 pandemic, we also consider the mental health of vulnerable groups such as the elderly, children, and adolescents. FIGURE 1 summarizes challenges and proposed solutions related to the COVID-19 pandemic, which are further discussed below in some detail.

\section{Social Isolation and Loneliness}

Social isolation and its impact on mental health is perhaps the most challenging aspect many individuals have faced this past year, notwithstanding those dealing with the virus directly. Although imposed lockdown policies have effectively curbed the spread of infection, social isolation instigated by quarantine has caused an increase of negative emotions and psychological effects, including confusion, anger, anxiety, and depression among the general populace $(7,8,12,30)$. In a study conducted by The Angus Reid Institute (a Canadian national not-for-profit research foundation), $50 \%$ of Canadians have reported that their mental health has worsened during the first lockdown (31). Another 42\% reported that their physical health has diminished due 
to inactivity (FIGURE 2) (31). Further, prolonged exposure to loneliness is a decisive risk factor for post-traumatic stress disorder symptoms (PTSS) and is associated with the development of minor psychiatric disorders and an increase in suicide risk $(32,33)$.

Loneliness among the elderly has also sharply increased as a result of the lockdown (28). The elderly are extremely vulnerable to the effects of loneliness as their social circles typically decline with age. Further, with the isolation orders preventing participation at places of worship, community centers, and daycare venues, compounded with fears of abandonment and neglect, there has been an increase in the prevalence of social disconnectedness, anxiety, and depression among the elderly $(9,29,30)$. Additionally, isolation of the elderly puts them at a greater risk of neurocognitive decline (31), autoimmune and cardiovascular disease (32), as well as decreases in sleep quality and increases in sleep disturbances (33).

The negative consequences of loneliness are not restricted to the elderly. They can affect youth and adults, noted by a 5.5\% increase in the perception of loneliness among middle-aged adults in the UK (34). In Canada, 20-25\% of Canadians aged 18 to 54 have increased the amount of alcohol they drink due to distancing measures, and sales of cannabis have reportedly increased $(41,42)$. Further, as youths are at a period of social and cognitive transition, the lockdown can significantly hinder the development of their social skills and identity, which can translate into immediate and long-term consequences (43). Further, youths have a higher risk of developing mental health symptoms such as anxiety and depression in the long-term, compared to adults, as their ability to cope with distressing situations and emotions may not be fully developed (16).

\section{Anxiety and Depression}


The fear of contracting and spread COVID-19 has caused a great deal of mental distress among the general populace (44). It has caused an increase in the prevalence of stress, anxiety disorders, and depression (45). Distress and anxiety disorders, driven by concerns and self-awareness of their health, were exceptionally high among individuals who had access to higher education(46). The use of social media has also shown to increase anxiety due to confusion brought on by the large volume and frequent circulation of disinformation, false reports about COVID-19, and high frequency of unpleasant news (47). High levels of anxiety in the population were also driven by the lockdown, which had caused economic decline (48), and disruptions to educational and professional development $(15,16)$. The measures taken to shut down most sectors of the economy during the spread of COVID-19 have resulted in sudden and unforeseen mass unemployment. This has predominantly affected poor and non-democratic nations because of the absence of countervailing economic measures. This issue is also wildly prevalent in Canada and should not be dismissed because the complexity of implementing massive subsides will leave many people vulnerable to poverty and its mental health consequences, such as anxiety and depression. In a study conducted by Nanos Research, 38.9\% of Canadians responded that personal financial hardship/debt concerns them most about the personal impact the current COVID-19 outbreak has on their lives (49), which can be seen as a contributing factor to the stress many Canadians are feeling (FIGURE 3).

Depression and anxiety were also greatly increased among the elderly due to the pandemic $(50,51)$. While the uncertainty and fears of contracting and spreading COVID-19 have primarily driven feelings of anxiety, social isolation has further exacerbated the pandemic's mental sequelae (34). Feelings of neglect can also arise among individuals who do not have access to the assistance necessary to maintain their health and care (52). Deficiencies in maintaining standards in their 
hygienic and dietary habits can also contribute significantly to depression and anxiety (50). Among the elderly who are dependent on the assistance of family, friends, or neighbors, there has also been an increase in feelings of being a burden and a sense of worthlessness, which leads to frustration, depression, and anxiety $(36,53)$.

While children and adolescents are unlikely to experience a severe COVID-19 infection (54), a combination of stay-at-home orders and an increasingly stressful life at home can negatively influence their social, cognitive, and emotional development (55-57). Children from low socioeconomic backgrounds are especially vulnerable to domestic violence and child maltreatment $(56,58,59)$. School closures have also driven increases in feelings of anxiety $(22-25 \%)$ and depression (17-20\%) due to pressures to maintain academic success during the transition to online schooling $(60,61)$.

\section{Suicide Risk}

As the pandemic continues to spread and restrictive lockdown measures remain in place, there have been growing concerns that the chronic anxiety and stress caused directly by the pandemic, coupled with the social and economic difficulties that have arisen, may increase suicide risk and self-harm among the population $(48,62,63)$. While evidence from the previous SARS epidemic found an increase in suicide risk following the outbreak (64), less can be stated with confidence from current longitudinal studies, as the pandemic was a repetitively recent phenomenon.

Several factors can contribute to increased suicide risk among the population. It has been suggested that survivors of COVID-19 are at increased suicide risk due to the psychological trauma from the fear of spreading the disease, thanatophobia, and the stigmatization that follows infection with COVID-19 $(63,65)$. Trauma may be more pronounced among patients with severe COVID-19 
infections, as individuals who required admission to the ICU were at higher risk of developing post-traumatic stress disorder and post-traumatic stress symptoms $(66,67)$. Additionally, lockdowns to control the spread of COVID-19 have also introduced a high degree of economic instability and greatly increased the unemployment rate worldwide (18). As economic difficulties have previously been shown to contribute to suicide risk (62), suicide rates have been projected to increase following the COVID-19 pandemic (69).

Evidence from the 2003 SARS epidemic suggests that suicide risk is higher among the elderly, especially among women, and individuals who were dependent on caregivers to maintain a reasonable standard of living (70,71). In the context of the COVID-19 pandemic, older individuals who feel that they lack social cohesion, or have been prevented from participating in social gatherings due to lockdown, are more vulnerable to suicide as they feel more disconnected from society $(36,53)$. Suicide risk among the elderly is further exacerbated by feelings of being devalued or perceived as a burden, such as when the elderly were passed over in priority for treatment when medical resources were in short supply (72). While suicide rates among children and adolescents in the general population have not largely been influenced by the COVID-19 pandemic thus far (73), stay-at-home mandates can still negatively influence youth's mental health, which could translate to increased suicide risk later in life. In particular, as families are forced to stay home throughout the pandemic, there has been an increase in domestic violence and child maltreatment $(56,58,74)$. The increased stress levels among parents and the in-home scenario produced by the pandemic can exacerbate the aggression and abuse towards children. While vulnerable youth would often rely on support systems such as childcare and school staff, it becomes much harder to do so with quarantine and stay at home orders (75). Adverse childhood experiences, such as domestic violence, sexual abuse, and neglect, are strong contributors to suicide risk. Especially at 
risk are populations of physically or mentally impaired youth, identify as part of the LGBT community, or have a history of abusing illicit substances. Youths from these demographic groups that have been isolated at home could also see an increase in self-harm (76).

\section{Post-Traumatic Stress Symptoms}

Similar to the SARS outbreak $(70,77)$, contracting COVID-19 can lead to post-illness posttraumatic stress disorder (PTSD) and can manifest several symptoms such as insomnia, depression, and anxiety $(66,78,79)$. Studies have shown that post-traumatic stress symptoms (PTSS) can persist for prolonged periods of up to and beyond 30 months (80), and in part, are driven by anxiety and fear of being discriminated against and stigmatized (78). As such, mental care should be considered for COVID-19 survivors. Aside from the direct effects of COVID-19 infection, the pandemic has exposed populations to prolonged periods of fear(81), as well as emotional and behavioral changes due to lockdown and physical distancing. Among the general populace, people from lower educational backgrounds and families with lower socioeconomic status were more likely to use negative coping strategies leading to the development of PTSS $(82,83)$. In particular, there was a higher prevalence of PTSD/PTSS sub-symptoms, such as negative alternations in cognition, mood, and poorer quality of sleep patterns, which were more prevalent in females than males (84).

\section{Sleep Disorders}

In addition to the pandemic lockdown's adverse psychological and mental effects, its immediate effects had also caused reductions in the quality and quantity of sleep in the broader population (85-87). These disruptions in the general populace's sleeping patterns in lockdown have mainly been driven by the drastic changes in daily schedule and patterns, which has delayed regular bedtime (85), caused an increase in difficulty to fall asleep, and increased the frequency of sleep 
disturbances $(88,89)$. Increased sedentary lifestyles, decreased exposure to natural light, decreases in social interaction, boredom, as well as increased screen time and consumption of social media also contribute to disruptions in natural sleep times and cause sleep disturbances (90).

Psychological factors have also contributed dramatically to sleep disturbances and patterns. In particular, high levels of anxiety, depression, loneliness, and uncertainty are strong predictors for the presence of insomnia and poor sleep quality $(87,91)$. This was also demonstrated in a Greek population where cases of insomnia and poorer sleep quality significantly increased in prevalence shortly after the COVID-19 outbreak (92). Further, disadvantaged individuals, such as those who experienced the economic consequences of the lockdown or expressed concern regarding their education or career, are more likely to suffer from sleep disturbances and poorer sleep quality(86).

Interestingly, while the psychologically burdened subpopulations are likely to experience decreases in sleep quality, some studies have suggested that the lockdown has not greatly affected the prevalence of sleep disorders (93) and suggests that the disruptions from the social routine allow for more time available and flexibility for individual sleep adaptation (94), leading to improvement of sleep quality during the lockdown (95). Further, work from home orders may confer time savings due to a loss of commuting time, which can translate to more sleep time and allows for sleep and work schedules to become more closely aligned with the natural circadian rhythm (89). However, these findings do not extend to populations with elevated symptoms of anxiety, depression, and loneliness.

\section{Steps forward}

Mandated quarantine orders have led to a dramatic change in lifestyle behaviors and increased mental health issues such as feelings of loneliness and social disconnect. To better safeguard 
mental health during the pandemic, several steps can be taken, such as implementing digital technology for social activities, mental health checks, and telemedicine $(8,96)$. Through video calls, activities can be coordinated similarly to that of virtual workplaces and can help mitigate feelings of social disconnect. This can greatly reduce the rates of depression, loneliness, and suicide risk among the general population, especially with individuals who live alone or suffer from mental illness. The use of video calls and telemedicine also allow access to health care and effectively combat feelings of loneliness and abandonment, especially among the elderly population.

With the increase in technology use, it is natural that social media usage would increase during the pandemic (97). However, social media has been linked to increased anxiety and poor mental health $(97,98)$ due to frequent unfavorable news and large volumes of disinformation. Therefore, limiting the use of social media may prove beneficial to the general population's mental health. Lockdowns have also driven a significant increase in boredom, screen time, and greatly decreased physical activity, which can negatively affect mental and physical health (99). As previously mentioned, these factors can also contribute significantly to the development of poor sleep quality and sleeping patterns $(87,90,91)$. Developing a routine, especially one that includes regular physical exercise at home, as well as some exposure to natural light, could greatly improve sleeping patterns and decrease feelings of frustration driven by boredom. Further, developing schedules can significantly limit screen time among youth and greatly improve sleep quality (100).

The management of depression, suicide risk, and feelings of neglect within the vulnerable subpopulations, such as the elderly and youths, is a major concern. Among the older population, there has been increasing concern of elder abuse and neglect within long-term care homes $(101,102)$, highlighted by the concentrated numbers of COVID-19 related cases and mortalities 
among the residents. This underscores the necessity for stricter enforcement of health guidelines and the development of stringent policies that mandate a consistent and adequate standard of care. The mental well-being of the elderly and their families can be greatly improved by ameliorating the hygiene, attention, and quality of life in long-term care homes. Further, there are growing concerns of child maltreatment $(58,59)$ and an increase in suicide risk among marginalized youth communities (76). Providing adequate social support, particularly in poor socioeconomic standing areas, as well as providing appropriate intervention for violent domestic cases may potentially mitigate risks of isolation and suicide risk within youth populations (102-104).

\section{Long term predictions}

There is still a great deal of uncertainty of the future, and as the pandemic drags on, customs and socialization will need to continue to change in order to fulfill the eusocial nature of society. While we have previously discussed steps that can be taken to alleviate some of the pandemic's mental strain (105), these recommendations alone are insufficient to ameliorate and mental sequelae of isolation from vulnerable and isolated populations, such as the elderly, in the long term.

To better cope with the feelings of loneliness, there was an increase in pet adoptions, as humans looked for comfort from animal companions. While this option effectively combats loneliness and provides the benefit of long-term companionship, several demographic groups are limited in this option, given the cost of time, economic and physical responsibilities necessary to maintain a pet. As an alternative, we predict and recommend the rapid development of robotic and artificial intelligence (AI)-based companionship. We have seen that COVID-19 has resulted in a rapid shift to Zoom, Facebook, Teams, Mural, and other nonspecific platforms to bring people together, facilitate the exchange of ideas, and retain teamwork among colleagues. However, most existing tools are still underdeveloped, even though cloud computing has expanded in the last six years to 
support greater storage and access to data that many applications and services use, allowing remote workers to access corporate resources and continue working However, with the new communication style and remote work, businesses will face new threats and security will most likely move past the traditional firewall parameters and with this progress, new onboarding evaluations will develop with AI technology. Given the current progress and improvements on interactive AI design in their ability to interpret and respond to increasingly complex speech, verbal and nonverbal cues, AI also shows a promising avenue to counter the effects of loneliness during the quarantine.

The practicality of developing and utilizing AI and digital services is best highlighted through its current deployment throughout the manufacturing, medical research, and entertainment industries. While automatons and interactive AI are still relatively simple, previous studies on social assistive robots have shown that they can confer benefits to mental health, such as improve people's moods, ameliorating depression, as well as encouraging social interaction and connectedness(106). Further, due to the increase in demand for reliable and accessible public health, there has been a growing interest in developing interactive chatbots (107) and potentially robots, to assist with selfmanaging conditions.

As it currently stands, there have been no large-scale longitudinal studies examining the mental health benefits of interactive AI, current studies are limited in scope, and there remains the outstanding question of whether the use of technology is sufficient to replace human interaction. Regardless, there is ample evidence supporting the notion that humanoid robots can provide some social comfort and promote social connectivity as a whole. As such, we are optimistic regarding its development, and we advocate for the widespread use of interactive robots for vulnerable and neglected populations to combat loneliness in the future. 


\section{Conclusion}

This article aimed to review and summarize findings regarding the mental health effects of the COVID-19 pandemic and lockdown orders. Here, we highlighted the prevalence and underlying causes of anxiety, depression, suicide risk, PTSS, and sleep disorders during the COVID-19 pandemic. We have also offered suggestions that may help monitor and ameliorate mental health issues during the pandemic and lockdown. While there has been a great deal of research on the current state of mental health, the pandemic's long-term effects on the general population are not yet apparent as this has been a recent phenomenon. However, using previous experiences from past epidemics, such as SARS, MERS, and H1N1, and the COVID-19 pandemic, we can better equip ourselves to manage the future mental health crises that may arise. 


\section{References}

1. WHO Director-General's opening remarks at the media briefing on COVID-19-11 March 2020

[Internet]. [cited 2021 Jan 26]. Available from: https://www.who.int/director-

general/speeches/detail/who-director-general-s-opening-remarks-at-the-media-briefing-on-covid-

19---11-march-2020

2. Hsiang S, Allen D, Annan-Phan S, Bell K, Bolliger I, Chong T, et al. The effect of large-scale anticontagion policies on the COVID-19 pandemic. Nature. 2020;584:262-7.

3. Flaxman S, Mishra S, Gandy A, Unwin HJT, Mellan TA, Coupland H, et al. Estimating the effects of non-pharmaceutical interventions on COVID-19 in Europe. Nature. 2020;584:257-61.

4. Venkatesh A, Edirappuli S. Social distancing in covid-19: what are the mental health implications? BMJ. 2020;369:m1379.

5. Nicola M, Alsafi Z, Sohrabi C, Kerwan A, Al-Jabir A, losifidis C, et al. The socio-economic implications of the coronavirus pandemic (COVID-19): a review. Int J Surg. 2020;78:185-93.

6. Usher K, Bhullar N, Jackson D. Life in the pandemic: social isolation and mental health. J Clin Nurs. 2020;29:2756-7.

7. Hossain MM, Tasnim S, Sultana A, Faizah F, Mazumder H, Zou L, et al. Epidemiology of mental health problems in COVID-19: a review. F1000Research. 2020;9:636.

8. Galea S, Merchant RM, Lurie N. The mental health consequences of COVID-19 and physical distancing: the need for prevention and early intervention. JAMA Intern Med. 2020;180:817.

9. Lei L, Huang X, Zhang S, Yang J, Yang L, Xu M. Comparison of prevalence and associated factors of anxiety and depression among people affected by versus people unaffected by quarantine during 
the COVID-19 epidemic in southwestern China. Med Sci Monit Int Med J Exp Clin Res. 2020;26:e924609.

10. Parola A, Rossi A, Tessitore F, Troisi G, Mannarini S. Mental health through the COVID-19 quarantine: agrowth curve analysis on Italian young adults. Front Psychol. 2020;11:567484.

11. Hwang T-J, Rabheru K, Peisah C, Reichman W, Ikeda M. Loneliness and social isolation during the COVID-19 pandemic. Int Psychogeriatr. 2020;32:1217-20.

12. Brooks SK, Webster RK, Smith LE, Woodland L, Wessely S, Greenberg N, et al. The psychological impact of quarantine and how to reduce it: rapid review of the evidence. Lancet Lond Engl. 2020;395:912-20.

13. Ahmed MZ, Ahmed O, Aibao Z, Hanbin S, Siyu L, Ahmad A. Epidemic of COVID-19 in China and associated psychological problems. Asian J Psychiatry. 2020;51:102092.

14. Xiang Y-T, Yang Y, Li W, Zhang L, Zhang Q, Cheung T, et al. Timely mental health care for the 2019 novel coronavirus outbreak is urgently needed. Lancet Psychiatry. 2020;7:228-9.

15. Shanahan L, Steinhoff A, Bechtiger L, Murray AL, Nivette A, Hepp U, et al. Emotional distress in young adults during the COVID-19 pandemic: evidence of risk and resilience from a longitudinal cohort study. Psychol Med. 2020;1-10.

16. Power E, Hughes S, Cotter D, Cannon M. Youth mental health in the time of COVID-19. Ir J Psychol Med. 2020;37:301-5.

17. Cao W, Fang Z, Hou G, Han M, Xu X, Dong J, et al. The psychological impact of the COVID-19 epidemic on college students in China. Psychiatry Res. 2020;287:112934. 
18. Kawohl W, Nordt C. COVID-19, unemployment, and suicide. Lancet Psychiatry. 2020;7:389-90.

19. Team V, Manderson L. How COVID-19 reveals structures of vulnerability. Med Anthropol. 2020;39:671-4.

20. Banerjee D. 'Age and ageism in COVID-19': elderly mental health-care vulnerabilities and needs. Asian J Psychiatry. 2020;51:102154.

21. Codagnone C, Bogliacino F, Gómez C, Charris R, Montealegre F, Liva G, et al. Assessing concerns for the economic consequence of the COVID-19 response and mental health problems associated with economic vulnerability and negative economic shock in Italy, Spain, and the United Kingdom. PloS One. 2020;15:e0240876.

22. Imran N, Zeshan M, Pervaiz Z. Mental health considerations for children \& adolescents in COVID19 pandemic. Pak J Med Sci. 2020;36:S67-72.

23. Vigo D, Patten S, Pajer K, Krausz M, Taylor S, Rush B, et al. Mental Health of communities during the COVID-19 pandemic. Can J Psychiatry Rev Can Psychiatr. 2020;65(10):681-7.

24. Pfefferbaum B, North CS. Mental health and the Covid-19 pandemic. N Engl J Med. 2020;383(6):510-2.

25. Bagcchi S. Stigma during the COVID-19 pandemic. Lancet Infect Dis. 2020;20(7):782.

26. Killerby ME, Link-Gelles R, Haight SC, Schrodt CA, England L, Gomes DJ, et al. Characteristics Associated with hospitalization among patients with COVID-19 - Metropolitan Atlanta, Georgia, March-April 2020. MMWR Morb Mortal Wkly Rep. 2020;69(25):790-4. 
27. Millett GA, Jones AT, Benkeser D, Baral S, Mercer L, Beyrer C, et al. Assessing differential impacts of COVID-19 on black communities. Ann Epidemiol. 2020;47:37-44.

28. Webb Hooper M, Nápoles AM, Pérez-Stable EJ. COVID-19 and Racial/Ethnic Disparities. JAMA. $2020 ; 323(24): 2466-7$.

29. Coronavirus (COVID-19) related deaths by ethnic group, England and Wales - Office for National Statistics [Internet]. [cited 2021 Feb 23]. Available from:

https://www.ons.gov.uk/peoplepopulationandcommunity/birthsdeathsandmarriages/deaths/artic les/coronavirusrelateddeathsbyethnicgroupenglandandwales/2march2020to10april2020

30. Banerjee D, Rai M. Social isolation in Covid-19: the impact of loneliness. Int J Soc Psychiatry. 2020;66:525-7.

31. Kurl S, Korzinski D. Worry, Gratitude \& Boredom: As COVID-19 affects mental, financial health, who fares better; who is worse?. Angus Reid Institute [Internet]. 2020 April 27 [cited 2021 Feb 16]. Available from: https://angusreid.org/covid19-mental-health/?fbclid=IwAR27sghXOPakg8RkNmCATCzQ9pygfKfFfk6YJx48TQG7xd7IFYNwON97w4

32. Lu W, Wang H, Lin Y, Li L. Psychological status of medical workforce during the COVID-19 pandemic: A cross-sectional study. Psychiatry Res. 2020;288:112936.

33. Liu JJ, Bao Y, Huang X, Shi J, Lu L. Mental health considerations for children quarantined because of COVID-19. Lancet Child Adolesc Health. 2020;4:347-9.

34. Armitage R, Nellums LB. COVID-19 and the consequences of isolating the elderly. Lancet Public Health. 2020;5:e256. 
35. Sepúlveda-Loyola W, Rodríguez-Sánchez I, Pérez-Rodríguez P, Ganz F, Torralba R, Oliveira DV, et al. Impact of social isolation due to COVID-19 on health in older people: mental and physical effects and recommendations. J Nutr Health Aging. 2020;24:938-947.

36. Santini ZI, Jose PE, York Cornwell E, Koyanagi A, Nielsen L, Hinrichsen C, et al. Social disconnectedness, perceived isolation, and symptoms of depression and anxiety among older Americans (NSHAP): a longitudinal mediation analysis. Lancet Public Health. 2020;5:e62-70.

37. Luchetti M, Terracciano A, Aschwanden D, Lee JH, Stephan Y, Sutin AR. Loneliness is associated with risk of cognitive impairment in the survey of health, ageing and retirement in Europe. Int J Geriatr Psychiatry. 2020;35:794-801.

38. Valtorta NK, Kanaan M, Gilbody S, Hanratty B. Loneliness, social isolation and risk of cardiovascular disease in the English longitudinal study of ageing. Eur J Prev Cardiol. 2018;25:1387-96.

39. Huang Y, Zhao N. Generalized anxiety disorder, depressive symptoms and sleep quality during COVID-19 outbreak in China: a web-based cross-sectional survey. Psychiatry Res. 2020;288:112954.

40. Käll A, Jägholm S, Hesser H, Andersson F, Mathaldi A, Norkvist BT, et al. Internet-based cognitive behavior therapy for loneliness: apilot randomized controlled trial. Behav Ther. 2020;51:54-68.

41. Ontario and Quebec cannabis distributors see sales spike amid COVID-19 pandemic. Global News [Internet]. 2020Mar 16. [cited2021 Feb 16]. Available from: https://globalnews.ca/news/6686754/cannabis-sales-coronavirus-pandemic/

42. $25 \%$ of Canadians (aged 35-54) are drinking more while at home due to COVID-19 pandemic. Canadian Center on Substance Use and Addiction \& Nanos [Internet]. 2020 April. [cited 2021 Feb 
16]. Available from: https://www.ccsa.ca/covid-19-and-increased-alcohol-consumption-nanospoll-summary-report

43. Matthews T, Danese A, Caspi A, Fisher HL, Goldman-Mellor S, Kepa A, et al. Lonely young adults in modern Britain: findings from an epidemiological cohort study. Psychol Med. 2019;49:268-77.

44. Wang C, Pan R, Wan X, Tan Y, Xu L, Ho CS, et al. Immediate psychological responses and associated factors during the initial stage of the 2019 coronavirus disease (COVID-19) epidemic among the general population in China. Int J Environ Res Public Health. 2020;17:1729.

45. Salari N, Hosseinian-Far A, Jalali R, Vaisi-Raygani A, Rasoulpoor S, Mohammadi M, et al. Prevalence of stress, anxiety, depression among the general population during the COVID-19 pandemic: a systematic review and meta-analysis. Glob Health. 2020;16:57.

46. Qiu J, Shen B, Zhao M, Wang Z, Xie B, Xu Y. A nationwide survey of psychological distress among Chinese people in the COVID-19 epidemic: implications and policy recommendations. Gen Psychiatry. 2020;33:e100213.

47. Gao J, Zheng P, Jia Y, Chen H, Mao Y, Chen S, et al. Mental health problems and social media exposure during COVID-19 outbreak. PLOS ONE. 2020;15:e0231924.

48. Reger MA, Stanley IH, Joiner TE. Suicide mortality and coronavirus disease 2019-aperfect storm? JAMA Psychiatry. 2020;77:1093-1094.

49. Canadians report an increase in feeling stressed regularly or all the time now compared to one month before COVID-19 MHCC Summary Report. Mental Health Commission of Canada \& Nanos [Internet]. 2020 May. [cited 2021 Feb 16]. Available from: https://www.mentalhealthcommission.ca/sites/default/files/2020-05/nanos_covid_may_2020.pdf 
50. Yildirim H, Işik K, Aylaz R. The effect of anxiety levels of elderly people in quarantine on depression during covid-19 pandemic. Soc Work Public Health. 2021;0:1-11.

51. Meng H, Xu Y, Dai J, Zhang Y, Liu B, Yang H. Analyze the psychological impact of COVID-19 among the elderly population in China and make corresponding suggestions. Psychiatry Res. 2020;289:112983.

52. Yang Y, Li W, Zhang Q, Zhang L, Cheung T, Xiang Y-T. Mental health services for older adults in China during the COVID-19 outbreak. Lancet Psychiatry. 2020;7:e19.

53. Wand APF, Zhong B-L, Chiu HFK, Draper B, De Leo D. COVID-19: the implications for suicide in older adults. Int Psychogeriatr. 2020;32:1225-30.

54. Sinha IP, Harwood R, Semple MG, Hawcutt DB, Thursfield R, Narayan O, et al. COVID-19 infection in children. Lancet Respir Med. 2020;8:446-7.

55. Masonbrink AR, Hurley E. Advocating for children during the COVID-19 school closures. Pediatrics [Internet]. 2020 Sep 1 [cited 2021 Jan 22];146. Available from: https://pediatrics.aappublications.org/content/146/3/e20201440

56. Brown SM, Doom JR, Lechuga-Peña S, Watamura SE, Koppels T. Stress and parenting during the global COVID-19 pandemic. Child Abuse Negl. 2020;110:104699.

57. Phelps C. Children and the COVID-19 pandemic. [Internet]. Vol. 12, Psychological Trauma: Theory, Research, Practice, and Policy. US: Educational Publishing Foundation; 2020 Aug[cited 2021 Jan 22]. p. S73. Available from: /fulltext/2020-39582-001.html 
58. Lawson M, Piel MH, Simon M. Child maltreatment during the COVID-19 pandemic: consequences of parental job loss on psychological and physical abuse towards children. Child Abuse Negl. 2020;110:104709.

59. Griffith AK. Parental burnout and child maltreatment during the COVID-19 pandemic. J Fam Violence. 2020;1-7. doi: 10.1007/s10896-020-00172-2. Epub ahead of print. PMID: 32836736.

60. Tang S, Xiang M, Cheung T, Xiang Y-T. Mental health and its correlates among children and adolescents during COVID-19 school closure: The importance of parent-child discussion. J Affect Disord. 2021;279:353-60.

61. Duan L, Shao X, Wang Y, Huang Y, Miao J, Yang X, et al. An investigation of mental health status of children and adolescents in china during the outbreak of COVID-19. J Affect Disord. 2020;275:1128.

62. Gunnell D, Appleby L, Arensman E, Hawton K, John A, Kapur N, et al. Suicide risk and prevention during the COVID-19 pandemic. Lancet Psychiatry. 2020;7:468-71.

63. Sher L. Are COVID-19 survivors at increased risk for suicide? Acta Neuropsychiatr. 2020;32:270270.

64. Zortea TC, Brenna CTA, Joyce M, McClelland H, Tippett M, Tran MM, et al. The impact of infectious disease-related public health emergencies on suicide, suicidal behavior, and suicidal thoughts. Crisis. 2020;1-14. doi: 10.1027/0227-5910/a000753. Epub ahead of print. PMID: 33063542.

65. Guo Q, Zheng Y, Shi J, Wang J, Li G, Li C, et al. Immediate psychological distress in quarantined patients with COVID-19 and its association with peripheral inflammation: a mixed-method study. Brain Behav Immun. 2020;88:17-27. 
66. Bo H-X, Li W, Yang Y, Wang Y, Zhang Q, Cheung T, et al. Posttraumatic stress symptoms and attitude toward crisis mental health services among clinically stable patients with COVID-19 in China. Psychol Med. 2020;1-2. doi: 10.1017/S0033291720000999. Epub ahead of print. PMID: 32216863; PMCID: PMC7200846.

67. McGiffin JN, Galatzer-Levy IR, Bonanno GA. Is the intensive care unit traumatic? What we know and don't know about the intensive care unit and posttraumatic stress responses. Rehabil Psychol. 2016;61:120-31.

68. Nordt C, Warnke I, Seifritz E, Kawohl W. Modelling suicide and unemployment: a longitudinal analysis covering 63 countries, 2000-11. Lancet Psychiatry. 2015;2:239-45.

69. Mclntyre RS, Lee Y. Projected increases in suicide in Canada as a consequence of COVID-19. Psychiatry Res. 2020;290:113104.

70. Chan SMS, Chiu FKH, Lam CWL, Leung PYV, Conwell Y. Elderly suicide and the 2003 SARS epidemic in Hong Kong. Int J Geriatr Psychiatry. 2006;21:113-8.

71. Yip PSF, Cheung YT, Chau PH, Law YW. The impact of epidemic outbreak: the case of severe acute respiratory syndrome (SARS) and suicide among older adults in Hong Kong. Crisis. 2010;31:86-92.

72. Rosenbaum L. Facing Covid-19 in Italy - ethics, logistics, and therapeutics on the epidemic's front line. N Engl J Med. 2020;382:1873-5.

73. Isumi A, Doi S, Yamaoka Y, Takahashi K, Fujiwara T. Do suicide rates in children and adolescents change during school closure in Japan? The acute effect of the first wave of COVID-19 pandemic on child and adolescent mental health. Child Abuse Negl. 2020;110:104680. 
74. Sidpra J, Abomeli D, Hameed B, Baker J, Mankad K. Rise in the incidence of abusive head trauma during the COVID-19 pandemic. Arch Dis Child. 2020;archdischild-2020-319872. doi:

10.1136/archdischild-2020-319872. Epub ahead of print. PMID: 32616522.

75. Clemens V, Deschamps P, Fegert JM, Anagnostopoulos D, Bailey S, Doyle M, et al. Potential effects of "social" distancing measures and school lockdown on child and adolescent mental health. Eur Child Adolesc Psychiatry. 2020;29(6):739-42.

76. Silliman Cohen RI, Bosk EA. Vulnerable youth and the COVID-19 pandemic. Pediatrics. 2020;146:e20201306.

77. Johal SS. Psychosocial impacts of quarantine during disease outbreaks and interventions that may help to relieve strain. N Z Med J. 2009;122:47-52.

78. Liu D, Baumeister RF, Veilleux JC, Chen C, Liu W, Yue Y, et al. Risk factors associated with mental illness in hospital discharged patients infected with COVID-19 in Wuhan, China. Psychiatry Res. 2020;292:113297.

79. Mazza MG, De Lorenzo R, Conte C, Poletti S, Vai B, Bollettini I, et al. Anxiety and depression in COVID-19 survivors: role of inflammatory and clinical predictors. Brain Behav Immun. 2020;89:594-600.

80. Mak IWC, Chu CM, Pan PC, Yiu MGC, Chan VL. Long-term psychiatric morbidities among SARS survivors. GenHospPsychiatry. 2009;31:318-26.

81. Zhang J, Lu H, Zeng H, Zhang S, Du Q, Jiang T, et al. The differential psychological distress of populations affected by the COVID-19 pandemic. Brain Behav Immun. 2020;87:49-50. 
82. Di Crosta A, Palumbo R, Marchetti D, Ceccato I, La Malva P, Maiella R, et al. Individual differences, economic stability, and fear of contagion as risk factors for PTSD symptoms in the COVID-19 emergency. Front Psychol. 2020;11:567367.

83. González-Sanguino C, Ausín B, Castellanos MÁ, Saiz J, López-Gómez A, Ugidos C, et al. Mental health consequences during the initial stage of the 2020 coronavirus pandemic (COVID-19) in Spain. Brain Behav Immun. 2020;87:172-6.

84. Liu N, Zhang F, Wei C, Jia Y, Shang Z, Sun L, et al. Prevalence and predictors of PTSS during COVID19 outbreak in China hardest-hit areas: gender differences matter. Psychiatry Res. 2020;287:112921.

85. Gupta R, Grover S, Basu A, Krishnan V, Tripathi A, Subramanyam A, et al. Changes in sleep pattern and sleep quality during COVID-19 lockdown. Indian J Psychiatry. 2020;62:370-8.

86. Beck F, Léger D, Fressard L, Peretti-Watel P, Verger P. Covid-19 health crisis and lockdown associated with high level of sleep complaints and hypnotic uptake at the population level. J Sleep Res [Internet]. 2020 Jun 28 [cited 2021 Jan 29]; Available from: https://www.ncbi.nIm.nih.gov/pmc/articles/PMC7361195/

87. Xiao H, Zhang Y, Kong D, Li S, Yang N. Social capital and sleep quality in individuals who selfisolated for 14 days during the coronavirus disease 2019 (COVID-19) outbreak in January 2020 in China. Med Sci Monit Int Med J Exp Clin Res. 2020;26:e923921-1-e923921-8.

88. Pinto J, van Zeller M, Amorim P, Pimentel A, Dantas P, Eusébio E, et al. Sleep quality in times of Covid-19 pandemic. Sleep Med. 2020;74:81-5. 
89. Altena E, Baglioni C, Espie CA, Ellis J, Gavriloff D, Holzinger B, et al. Dealing with sleep problems during home confinement due to the COVID-19 outbreak: practical recommendations from a task force of the European CBT-I academy. J Sleep Res. 2020;29:e13052.

90. Nagata JM, Magid HSA, Gabriel KP. Screen time for children and adolescents during the coronavirus disease 2019 pandemic. Obesity. 2020;28:1582-3.

91. Janati Idrissi A, Lamkaddem A, Benouajjit A, Ben El Bouaazzaoui M, El Houari F, Alami M, et al. Sleep quality and mental health in the context of COVID-19 pandemic and lockdown in Morocco. Sleep Med. 2020;74:248-53.

92. Voitsidis P, Gliatas I, Bairachtari V, Papadopoulou K, Papageorgiou G, Parlapani E, et al. Insomnia during the COVID-19 pandemic in a Greek population. Psychiatry Res. 2020;289:113076.

93. Roitblat Y, Burger J, Leit A, Nehuliaieva L, Umarova GSh, Kaliberdenko V, et al. Stay-at-home circumstances do not produce sleep disorders: an international survey during the COVID-19 pandemic. J Psychosom Res. 2020;139:110282.

94. Blume C, Schmidt MH, Cajochen C. Effects of the COVID-19 lockdown on human sleep and restactivity rhythms. Curr Biol. 2020;30:R795-7.

95. Holzinger B, Mayer L, Nierwetberg F, Klösch G. COVID-19 lockdown - are Austrians finally able to compensate their sleep debt? Sleep Med X. 2021;3:100032.

96. Zhou X, Snoswell CL, Harding LE, Bambling M, Edirippulige S, Bai X, et al. The role of telehealth in reducing the mental health burden from COVID-19. Telemed J E-Health Off J Am Telemed Assoc. 2020;26:377-9. 
97. Drouin M, McDaniel BT, Pater J, Toscos T. How parents and their children used social media and technology at the beginning of the COVID-19 pandemic and associations with anxiety. Cyberpsychology Behav Soc Netw. 2020;23:727-36.

98. Hou F, Bi F, Jiao R, Luo D, Song K. Gender differences of depression and anxiety among social media users during the COVID-19 outbreak in China:a cross-sectional study. BMC Public Health. 2020;20:1648.

99. Colley RC, Bushnik T, Langlois K. Exercise and screen time during the COVID-19 pandemic. Health Rep. 2020;31:3-11.

100. Council on Communication and Media. Media and young minds. Pediatrics. 2016;138:e20162591.

101. Gardner W, States D, Bagley N. The coronavirus and the risks to the elderly in long-term care. J Aging Soc Policy. 2020;32:310-5.

102. Fisman DN, Bogoch I, Lapointe-Shaw L, McCready J, Tuite AR. Risk factors associated with mortality among residents with coronavirus disease 2019 (COVID-19) in long-term care facilities in Ontario, Canada. JAMA Netw Open. 2020;3:e2015957.

103. Monteith LL, Holliday R, Brown TL, Brenner LA, Mohatt NV. Preventing suicide in rural communities during the COVID-19 pandemic. J Rural Health Off J Am Rural Health Assoc Natl Rural Health Care Assoc. 2021;37:179-84.

104. Standish K. A coming wave: suicide and gender after COVID-19. J Gend Stud. 2021;30:114-8.

105. Higgins V, Sohaei D, Diamandis EP, Prassas I. COVID-19: from an acute to chronic disease? Potential long-term health consequences. Crit Rev Clin Lab Sci. 2020;0(0):1-23. 
106. Bemelmans R, Gelderblom GJ, Jonker P, de Witte L. Socially assistive robots in elderly care: a systematic review into effects and effectiveness. J Am Med Dir Assoc. 2012;13:114-120.e1.

107. Miner AS, Laranjo L, Kocaballi AB. Chatbots in the fight against the COVID-19 pandemic. NPJ Digit Med [Internet]. 2020 May 4 [cited 2021 Feb 11];3. Available from:

https://www.ncbi.nlm.nih.gov/pmc/articles/PMC7198587/ 


\section{FIGURE 1}

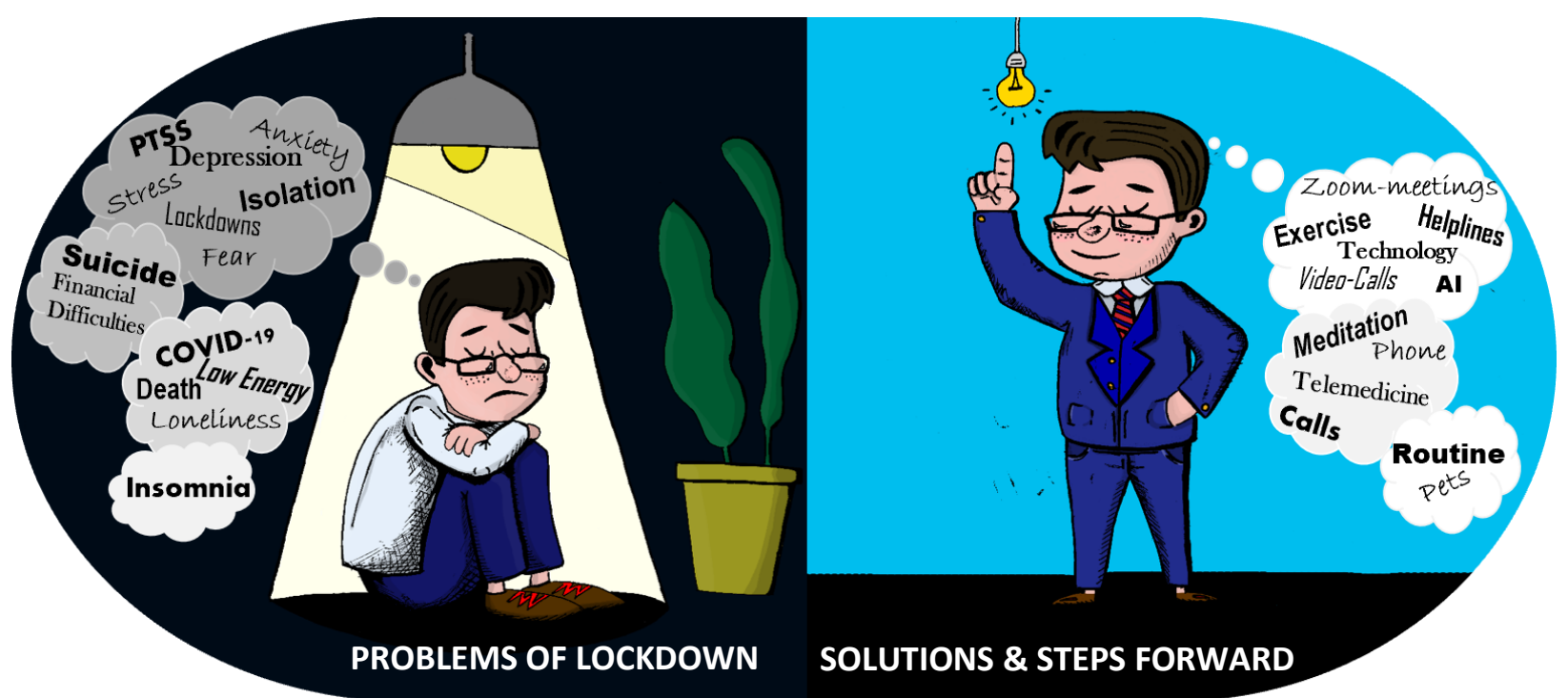

FIGURE1: Challenges people are facing during COVID-19 lockdowns and proposed solutions.

The figure summarizes key challenges mentioned and possible solutions suggested in the paper. Fonts and sizes are randomized and do not correlate to any data. The illustration is a synopsis of points that are further elaborated upon in the paper.

Abbreviations: PTSS (Post Traumatic Stress Symptoms) \& Al (Artificial Intelligence) 


\section{FIGURE 2}

\section{Mental health and physical well-being since COVID 19 shutdown (All respondents, $\mathrm{n}=\mathbf{1 , 9 1 2}$ )}

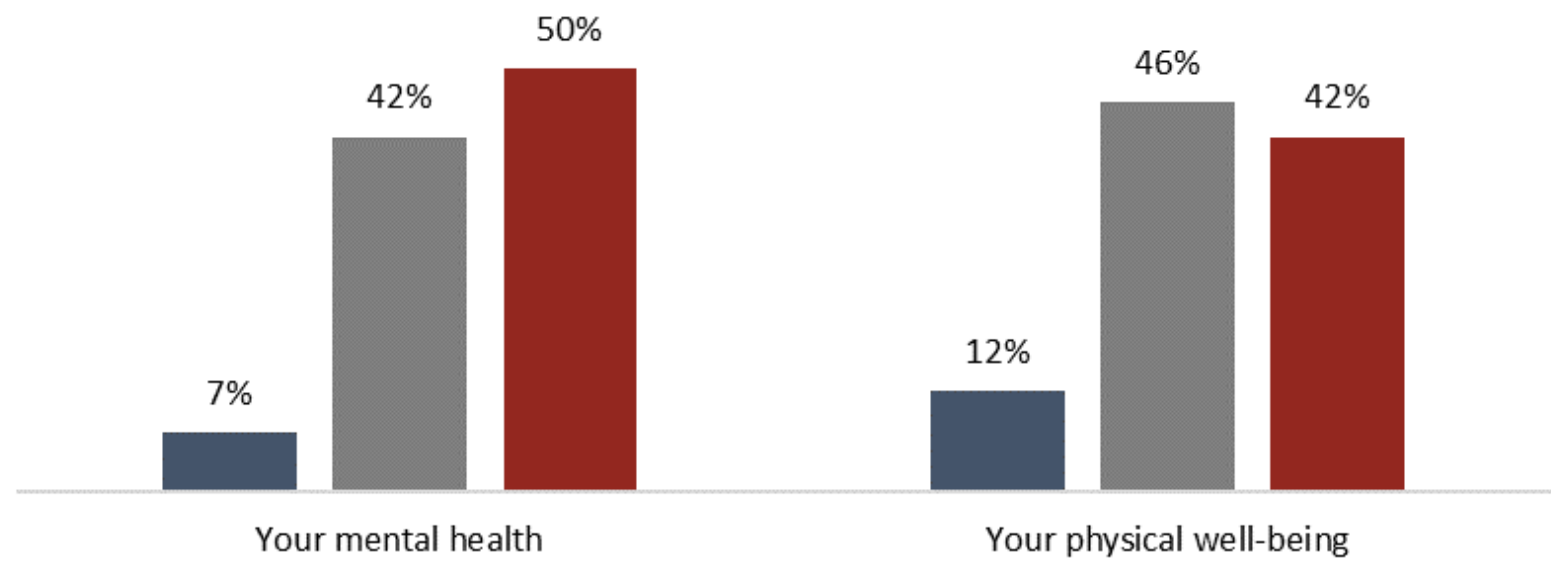

A lot/A little better than six weeks ago $n$ No change $n$ A little/A lot worse than six weeks ago

FIGURE2: Mental health and physical well-being since COVID 19 shutdown.

The figure contains data by the Angus Reid Institute from their online survey conducted from April 15 - 17, 2020, among a representative randomized sample of 1,912 Canadian adults. The estimated margin of error is about $2 \%$.are due to rounding. 


\section{FIGURE 3}

\section{FEELING OF STRESS}

Before COVID-19

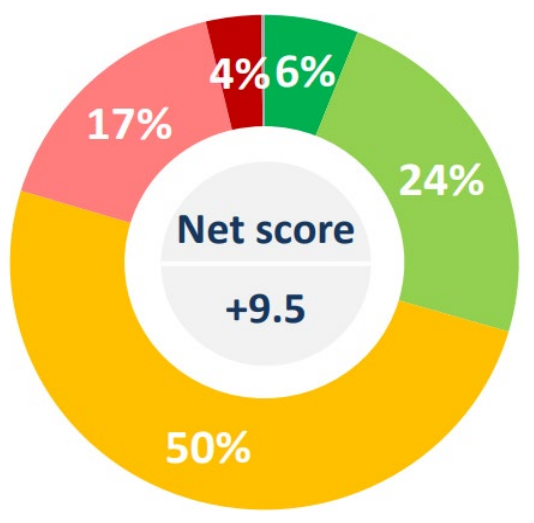

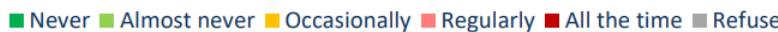

During April 2020

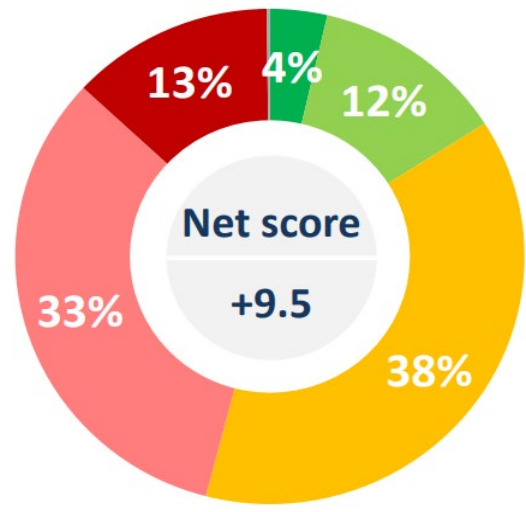

FIGURE 3: Feeling of Stress Before COVID-19 \& During April 2020.(A)Before COVID-19 pie-chart contains individual's answers to the following question: "Thinking of the months before the Covid-19 outbreak, did you feel stress never, almost never, occasionally, regularly or all the time?" (B) During April 2020 pie-chart contains individual's answers to the following question: "In the last month because of the Covid-19 outbreak have you felt stress never, almost never, occasionally, regularly or all the time?"

The figure was derived by Mental Health Commission of Canada and Nanos from their RDD dual hybrid telephone and online random survey conducted from April 25 - 27, 2020, among a representative randomized sample of 1,049 Canadian adults. The estimated margin of error of +/- 3.1 percentage points. 